\title{
O Desenvolvimento Rural no Estado do Rio de Janeiro a partir de Uma Análise Multidimensional ${ }^{1,2}$
}

\author{
Raquel Pereira de Souza ${ }^{3}$
}

Resumo: A pequena importância econômica da agropecuária para o estado do Rio de Janeiro não implica na inexistência de áreas rurais, mas, sim, que as áreas rurais do estado estejam diante de uma realidade em que outras funções dos espaços rurais estejam presentes (lazer, turismo) e que essa ruralidade seja capaz de fornecer processos virtuosos de desenvolvimento rural. Dessa forma, o presente artigo tem por objetivo analisar e comparar os processos de desenvolvimento rural no estado do Rio de Janeiro a partir de indicadores multidimensionais de desenvolvimento rural, resgatando seus determinantes. Para tanto, foi realizada uma adaptação da metodologia proposta por Kageyama (2008). Os dados necessários à construção dos indicadores foram coletados principalmente nos Censos Demográfico e Agropecuário do IBGE e no Ministério da Educação. A técnica estatística utilizada foi a análise fatorial e a de cluster. A análise apontou a existência de uma situação heterogênea em termos de desenvolvimento no espaço rural fluminense, havendo regiões onde o processo de desenvolvimento tem se mostrado virtuoso e associado à expansão do setor fabril e de serviços e outras situações em que o passivo dos ciclo do café e da cana levaram a situação oposta.

Palavras-chaves: indicadores, desenvolvimento rural, Rio de Janeiro, análise de clusters.

Abstract: The small economic importance of agriculture for Rio de Janeiro state does not imply the absence of rural areas, but rather that the rural areas of the state are facing a reality where other functions of rural areas are present (leisure and tourism) and that this situation is capable of providing virtuous rural development processes. Thus, this article aims to analyze and compare the process of rural development in Rio de Janeiro state from multidimensional indicators of rural development, rescuing its determinants. In order to do that, an adaptation of the methodology proposed by Kageyama (2008) was carried out. The necessary data to construct the indicators were collected mainly in the Demographic and Agricultural Census of IBGE and the Ministry of Education. The statistical technique used was factor analysis and cluster analysis. The analysis pointed out the existence of a heterogeneous situation in terms of development in the rural area of Rio

1. A partir de pesquisa financiada pela Fundação Carlos Chagas Filho de Amparo à Pesquisa do Estado do Rio de Janeiro (Faperj).

2. Data de submissão: 29 de agosto de 2016. Data de aceite: 22 de abril de 2018.

3. Universidade Federal Fluminense, Volta Redonda-RJ, Brasil. E-mail: raquel.p.souza@gmail.com 
de Janeiro, i.e., regions where the development process has been virtuous and associated with the expansion of the manufacturing and services sector and other situations where the coffee and sugarcane cycles have led to the opposite situation.

Key-words: indicators, rural development, Rio de Janeiro, cluster analysis.

Classificação JEL: O18, R11, R23.

DOI: http://dx.doi.org/10.1590/1234-56781806-94790570107

\section{Introdução}

O estado do Rio de Janeiro é um dos estados brasileiros com menor representatividade econômica da produção agropecuária, sendo muito mais conhecido nacional e internacionalmente por suas atrações turísticas. Contudo, o fato de a agropecuária estadual não ser expressiva em termos nacionais não significa que não haja áreas rurais, mas, sim, que a tônica da dinâmica de desenvolvimento dessas regióes aconteça de forma diferenciada de outras regiões do País onde a agropecuária é ainda importante para a dinâmica do meio rural.

Essa diferenças espaciais nos processos de desenvolvimento decorrem, antes de tudo, das mudanças sociais, econômicas, ambientais, institucionais, demográficas que definem os processos de desenvolvimento rural em cada estado da federação ou mesmo internamente a estes. Assim, diferenças territoriais em relação às dimensões antes citadas podem conformar diferentes trajetórias de desenvolvimento, ocasionando uma diversidade de situações no meio rural, sendo algumas marcadas pela forte produção agropecuária e outras marcadas pela forte presença da pluriatividade, por exemplo.

Entende-se que, no estado do Rio de Janeiro, a tônica do processo de desenvolvimento rural em curso já não esteja calcada na atividade agropecuária, como fora em outrora (como no ciclo do café, por exemplo), mas, sim, nas diferentes funções que o meio rural passou a ter no período recente: lazer (turismo rural, ecológico, cultural), moradia (diante da especulação imobiliária presente nos centros urbanos ou mesmo por opção daqueles que buscam melhor qualidade de vida) e produção de bens ligados a nichos de mercados (produtos orgânicos, artesanais, ligados à agricultura familiar regional). Essas novas funções estão relacionadas à características determinantes presentes no espaço fluminense, mesmo que de forma não uniforme, que são: o relevo acidentado, dificultando a produção agrícola e pecuária, o solo com pouca fertilidade, a tradição turística e o alto grau de urbanização.

As diferenças em termos de processo de desenvolvimento que marcam cada região rural podem ser apreendidas de forma simplificada através de indicadores, que fornecem uma fotografia da realidade, sendo possível, a partir dessa fotografia, resgatar e entender seus aspectos econômicos, sociais, demográficos, geográficos e institucionais determinantes. Assim, os indicadores contribuem para as discussões de ações e intervenções públicas e privadas mais qualificadas que considerem as heterogeneidades, promovendo um desenvolvimento rural virtuoso.

Há diferentes metodologias para a construção dos indicadores, dependendo das dimensões do desenvolvimento a serem apreendidas e o conceito de desenvolvimento a ser considerado. Disso resulta uma análise multidimensional que depende do ponto de vista do pesquisador em quais aspectos considerar em cada realidade (demográfica, social econômica, institucional, ambiental etc.), mas, também, a forma de compreender o desenvolvimento rural, ou seja, visto como um processo formado por etapas (em que os indicadores buscam refletir os fatores condicionantes, a trajetória e os resultados), ou um fim, em que o desenvolvimento estaria refletindo somente a qualidade de vida 
da população (sendo, assim, captado por indicadores de resultado do tipo IDH, taxa de alfabetização, renda, entre outros).

Neste contexto, o presente artigo tem por objetivos analisar e comparar o processo de desenvolvimento rural no estado do Rio de Janeiro a partir de indicadores multidimensionais de desenvolvimento rural, resgatando, na medida do possível, os seus determinantes econômicos, sociais históricos e geográficos. Isso implica que o desenvolvimento será abordado de forma processual, o que remete a considerar seus Fatores Condicionantes, suas Caraterísticas e os Resultados.

Além desta introdução, o artigo apresenta uma breve caracterização do estado do Rio de Janeiro, o referencial teórico que aborda o conceito e medida do desenvolvimento rural, a metodologia utilizada, a análise dos resultados e as conclusões, além das referências bibliográficas consultadas.

\section{Caracterização do estado do Rio de Janeiro: o rural e o urbano}

Apesar da pouca importância econômica da agropecuária, o estado do Rio de Janeiro tem significativa importância no cenário brasileiro. Segundo dados do
Instituto Brasileiro de Economia e Estatística (IBGE, 2014) foi responsável por $11,5 \%$ do PIB brasileiro em 2012 ficando somente atrás do estado de São Paulo.

Em termos político-administrativos, o estado é formado por oito grandes regiões: serrana, centro-sul fluminense, médio paraíba, costa verde, metropolitana, baixadas litorâneas, norte fluminense e noroeste fluminense (Figura 1).

O estado é altamente urbanizado e industrializado. Segundo o Censo Demográfico 2010 (IBGE, 2011), 97\% da população está nas áreas urbanas e 3\% estão nas áreas rurais. Segundo Moreira (2001), a exacerbada concentração da população, da renda, da poupança, de condições de desenvolvimento na região metropolitana do Rio de Janeiro gerou um forte desequilíbrio inter-regional, com exclusão política e social do interior. Esse intenso processo de urbanização no estado condicionou ainda as transformações no espaço rural, ampliando a prática do turismo rural e a disseminação de empregos não agrícolas (RUA, 2006).

A urbanização do estado está associada ao aumento da participação dos setores secundário e terciário na atividade econômica. Segundo dados do Ceperj (2009), $73,7 \%$ do valor adicionado gerado no Rio de Janeiro teve como origem o setor secundário, $26,3 \%$, o setor industrial e $0,5 \%$, o setor agropecuário. Essa pequena expressividade do valor agregado gerado pelo setor

Figura 1. Rio de Janeiro: municípios e regiões do governo

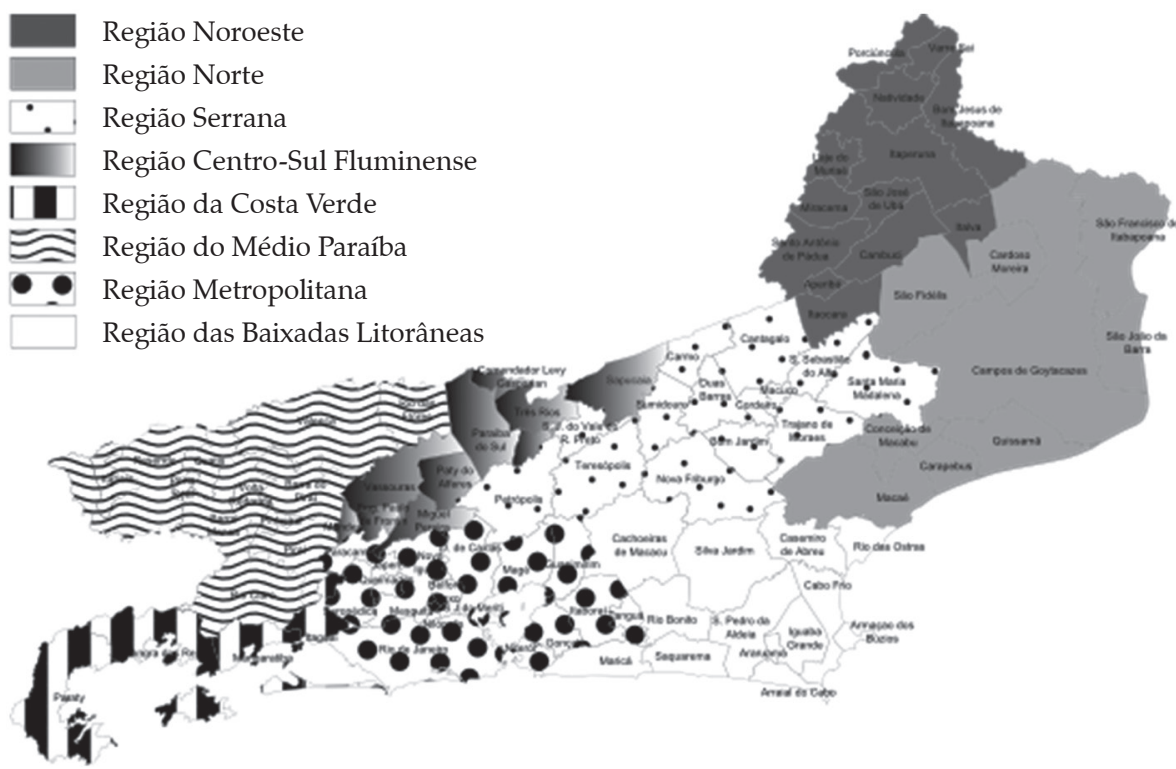

Fonte: Ceperj, 2013. 
agropecuário no estado demonstra a dependência das importações de produtos ligados à produção agropecuária, bem como reduz a possibilidade da existência de encadeamentos agroindustriais (SOBRAL, 2009). Em relação às atividades agropecuárias, as regiões norte fluminense e serrana destacam-se, gerando, em 2009 , cerca de $50 \%$ do valor adicionado pela agropecuária do estado (CEPERJ, 2009).

Teixeira (2009) coloca que

[...] a organização do espaço agrário fluminense exibe peculiaridades, tais como: desenvolvimento desordenado, deterioração ambiental, perda de terras agrícolas, intenso ritmo de urbanização associado à valorização acentuada da terra e o efeito da metropolização exercida pela cidade do Rio de Janeiro (p. 81).

Como consequência há um esvaziamento das práticas agrícolas no meio rural e um crescimento das atividades não agrícolas, impulsionado, ainda, pela atividade turística que, em maior ou menor grau, tem crescido nas áreas rurais em todo estado. Teixeira (2009), a partir da análise da evolução da renda e ocupação no meio rural, aponta haver um esvaziamento da prática agrícola, mas não um abandono do meio rural, pelo contrário, há uma ampliação e diversificação das ocupações não agrícolas no rural fluminense.

Nesse sentido, Ney (2010) coloca que as atividades não agrícolas no rural fluminense têm sido explicadas por motores exógenos, quais sejam: a) consumo urbano de turismo de praia de campo e de artesanato; b) demanda de áreas rurais próximas às cidades para construção de moradias pela população de baixa renda (GRAZIANO; DEL GROSSI, 1998). A esse respeito vale destacar que muitos municípios têm reduzido às áreas rurais com o objetivo de incorporar essas áreas à rede urbana e, portanto, tornar as residências desses espaços aptas ao pagamento do IPTU (Imposto Predial e Territorial Urbano), imposto cuja arrecadação é municipal (RUA, 2005); c) a transferência de residência da população urbana para o meio rural em busca de qualidade de vida (GRAZIANO; DEL GROSSI, 1998).

Por isso, no caso do estado do Rio de Janeiro, dado seu alto grau de urbanização, as demandas dos setores urbanos, independentes das atividades locais, passam a ter importância decisiva no desenvolvimento rural (NEY, 2010).

\section{O desenvolvimento rural: conceito e medida}

O termo "desenvolvimento rural" vem se alterando ao longo do tempo, incorporando novas variáveis de análise; contudo, há de se destacar que, apesar dessas mudanças, a essência, ou seja, o objetivo fim, que é a melhoria do bem-estar das populações rurais, estaria presente em todas elas. Navarro (2001) e Chalita (2005) destacam que o conceito de desenvolvimento rural altera-se ao longo do tempo, influenciado por diversas conjunturas e, principalmente, pelos novos condicionantes que o desenvolvimento geral da economia e da vida social impõe às famílias e às atividades rurais. É justamente pelo fato de as populações rurais fazerem parte da sociedade e sentirem as consequências das mudanças social e econômica que ocorrem nesta, que se torna difícil remeter ao fenômeno do desenvolvimento rural como evento dissociado do desenvolvimento urbano. Veiga (2000) infere não haver a separação concreta do desenvolvimento rural do desenvolvimento urbano. Sendo o desenvolvimento um processo complexo, é necessária a simplificação, separando o lado rural do desenvolvimento. Kageyama (2004) aponta que o mesmo só pode ser definido por meio de simplificações, que incluem "decomposição" de alguns de seus aspectos e "aproximação" por algumas formas de medidas.

Assim, Kageyama (2006) coloca que o desenvolvimento rural deve englobar o aspecto econômico, que implica no aumento do nível e estabilidade da renda familiar, o aspecto social que implica em nível de vida socialmente aceitável e que a trajetória desse fenômeno esteja calcada na diversificação das atividades que geram renda (pluriatividade).

Para Mattos (2006), a pluriatividade têm contribuído preponderantemente para o desenvolvimento rural nas localidades onde esse fenômeno se verifica com maior intensidade; isso porque esse ela se apresenta como alternativa a alguns dos principais problemas que afetam as populações rurais, tais como a geração de emprego, a melhoria da renda, a redução da vulnerabilidade social e produtiva, o êxodo dos mais jovens, a dificuldade de gestão interna das unidades familiares, entre outros.

Contudo, avaliar o fenômeno do desenvolvimento rural torna-se tarefa difícil, sendo necessário casar o conceito de desenvolvimento utilizado com as dimensões 
consideradas e com a disponibilidade de dados. $\mathrm{Ou}$ seja, utilizar indicadores de desenvolvimento significativos diante do conceito utilizado e para os quais haja disponibilidades de dados. Importante também é "obter medidas passíveis de comparação entre regióes e ao longo do tempo para captar de forma mais adequada à evolução do fenômeno" (KAGEYAMA, 2006, p. 31).

Segundo Wye Group (2011), há três aspectos que devem ser considerados na análise do desenvolvimento: 1) o território, pois o desenvolvimento é um conceito espacialmente localizado, uma vez que os territórios possuem diferentes, opções, perspectivas e oportunidades; 2) os temas abordados, o desenvolvimento é conceito multissetorial (demográfico, social, econômico, ambiental); 3) o tempo, pois o desenvolvimento é um conceito dinâmico, uma vez que a evolução histórica, as mudanças de atitudes da sociedade e as mudanças nas estruturas econômicas têm como efeito alterações no processo de desenvolvimento.

Conterato, Schneider e Waquil (2009) argumentam que a criação de indicadores de desenvolvimento rural estaria associada à percepção de que as desigualdades regionais, em termos de desenvolvimento rural, poderiam ser captadas através da simplificação e que o conceito e o processo do desenvolvimento trazem consigo diferentes formas de apreensão e determinantes das suas manifestações.

As diferentes facetas e seus determinantes que envolvem a noção de desenvolvimento rural estão relacionadas à heterogeneidade imposta pelas dotações geográficas e pela ocupação histórica do território (KAGEYAMA, 2008). Portanto, o resgate da história, dos aspectos geográficos, tais como relevo, clima, vegetação e principais eventos sociais e econômicos da região, dentre outros fatores, possibilita compreender como se construiu a dinâmica do desenvolvimento nas regiões.

Assim, existe um amplo conjunto de temas (por exemplo, bem-estar social, meio ambiente, bem-estar econômico, capital social, capital físico, acesso a mercados, dentre outros) e indicadores que podem ser considerados para avaliar o desenvolvimento rural. A seleção de cada um deles dependerá da visão de desenvolvimento utilizada. Em decorrência dessas diferenças que instituições internacionais, tais como FAO, Global Strategy", União Europeia, OECD, têm

4. A Estratégia Global tem por objetivo fornecer a estrutura para um sistema de estatística nacional e internacio- proposto diferentes conjuntos de indicadores com o objetivo de avaliar o desenvolvimento rural em diferentes países e regiões (WYE GROUP, 2011).

Em termos nacionais, Kageyama (2004) propôs o Índice de Desenvolvimento Rural (IDR), que foi e ainda vem sendo utilizado por diversos autores para avaliar o desenvolvimento rural em diferentes situações (MELO, 2005; SILVA, 2006; MELO; PARRÉ, 2007; CONTERATO; SCHNEIDER; WAQUIL, 2009; ARAÚJO, 2014). Kageyama (2008) também buscou avaliar e comparar o desenvolvimento rural entre os diferentes estados que compõem a Federação utilizando uma metodologia mais complexa que o IDR, a qual desagrega o fenômeno em três dimensões: 1) Fatores Condicionantes; 2) Características e 3) Resultados, sendo essa metodologia utilizada no presente artigo. O uso dessa metodologia para analisar o desenvolvimento rural em municípios até então era inédita, provavelmente em virtude do grau de dificuldade de se criar indicadores a partir do que há disponível de dados para o nível municipal.

\section{Indicadores de desenvolvimento: da teoria à prática}

Não há um único conceito de desenvolvimento rural; no entanto, todos os conceitos existentes destacam a melhoria das condições de vida da população rural. Kageyama (2004) extrai, a partir de uma revisão de literatura sobre o tema, a ideia de que o desenvolvimento rural deva combinar o aspecto econômico (aumento do nível e estabilidade da renda familiar) e o aspecto social (obtenção de um nível de vida socialmente aceitável), e que sua trajetória principal possa residir na diversificação das atividades que geram renda (pluriatividade). A partir dessa constatação Kageyama (2008) propõe uma metodologia de avaliação do desenvolvimento nas áreas rurais baseada em dados secundários calcada em três dimensões: 1) identificação dos Fatores Condicionantes do desenvolvimento rural, em que busca-se levantar indicadores que caracterizem a base demográfica e econômica, que é sob as quais se desenrola o processo de desenvolvimento rural; 2) Características do desenvolvimento rural, nas

nal para gerar dados básicos e informações para guiar a tomada de decisão no século XXI. 
Quadro 1. Adaptação dos indicadores propostos por Kageyama

\begin{tabular}{|c|c|c|}
\hline \multirow{16}{*}{ 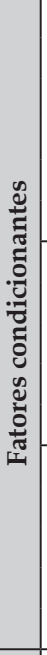 } & \multirow{6}{*}{$\begin{array}{l}\text { Fatores } \\
\text { demográficos }\end{array}$} & $\%$ de estabelecimentos de ensino fundamental com mais que 30 alunos na área rural \\
\hline & & \% de turmas não - multisseriadas de ensino fundamental nas áreas rurais \\
\hline & & Razão docente por população de 5 a 14 anos (por mil pessoas) na área rural \\
\hline & & PIBpc municipal (mil R\$/ano) \\
\hline & & Razão docente por estabelecimentos de ensino fundamental e médio na área rural \\
\hline & & Razão de dependência (ativos/inativos) na área rural \\
\hline & \multirow{5}{*}{$\begin{array}{l}\text { Isolamento } \\
\text { territorial }\end{array}$} & \% da população municipal residente na área rural \\
\hline & & $\%$ dos domicílios rurais com telefone (fixo e celular) \\
\hline & & $\%$ dos domicílios rurais com internet \\
\hline & & Densidade demográfica $\left(\mathrm{hab} / \mathrm{km}^{2}\right)$ \\
\hline & & Veículos $/ \mathrm{km}^{2}$ \\
\hline & \multirow{5}{*}{$\begin{array}{l}\text { Presença da } \\
\text { agricultura } \\
\text { familiar }\end{array}$} & $\%$ área plantada exceto as duas principais culturas \\
\hline & & \% da área plantada em estabelecimentos com até 10 hectares (ha) \\
\hline & & \% do valor da produção com origem na agricultura familiar \\
\hline & & \% da mão de obra familiar não assalariada na área rural \\
\hline & & Área média dos estabelecimentos agropecuários hectares (ha) \\
\hline \multirow{11}{*}{ 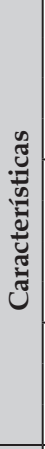 } & \multirow{4}{*}{$\begin{array}{l}\text { Diversidade da } \\
\text { agricultura }\end{array}$} & Relação entre área de lavoura e de outros usos \\
\hline & & Razão entre pastagens plantadas e naturais \\
\hline & & Razão entre o valor da produção por área (ha) \\
\hline & & Valor da produção por pessoa ocupada na área rural (R\$/pessoa) \\
\hline & \multirow{4}{*}{ Ambientais } & \% da área dos estabelecimentos rurais com matas e/ou florestas \\
\hline & & $\%$ de estabelecimentos agropecuários que utilizam plantio em nível \\
\hline & & $\%$ estabelecimentos agropecuários que protegem encostas \\
\hline & & \% estabelecimentos agropecuários que utilizam rotação de cultura \\
\hline & \multirow{3}{*}{ Pluriatividade } & \% do pessoal ocupado apenas em atividades não agropecuárias nos estabelecimentos agropecuários \\
\hline & & $\%$ dos estabelecimentos agropecuários que são pluriativos \\
\hline & & $\%$ da receita dos estabelecimentos agropecuários com origem no trabalho não agrícola \\
\hline \multirow{9}{*}{ 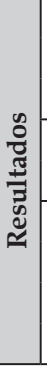 } & \multirow{3}{*}{ Escolaridade } & Taxa (\%) de escolaridade da população rural \\
\hline & & Razão de pessoas com 15 anos ou mais por pessoas com 8 anos ou mais de estudo \\
\hline & & Taxa (\%) de Alfabetização \\
\hline & \multirow{2}{*}{ Êxodo rural } & Variação (\%) da população rural residente entre 2000 e 2010 \\
\hline & & Média de moradores nos domicílios rurais \\
\hline & \multirow{4}{*}{$\begin{array}{l}\text { Renda e redução } \\
\text { da pobreza }\end{array}$} & Índice de Desenvolvimento Humano Municipal (IDHm) \\
\hline & & Índice de Condições de Vida (INIVI) \\
\hline & & $\%$ da receita dos estabelecimentos agropecuários vindo do trabalho \\
\hline & & Rendimento médio mensal das pessoas com 10 ou mais anos (R\$/pessoa) \\
\hline
\end{tabular}

Fonte: Elaborado pela autora.

quais estão presentes indicadores que buscam identificar as características socioeconômicas e ambientais do desenvolvimento em questão; 3) Efeitos ou Resultados do processo de desenvolvimento, onde os indicadores presentes expõem as consequências (positivas e negativas) do processo em questão.

A partir dessa construção teórica, a autora propõe uma série de indicadores com objetivo de analisar as três dimensões do desenvolvimento rural ${ }^{5}$. Contudo, para o cálculo dos indicadores propostos por

5. Os indicadores podem ser consultados em Kageyama (2008).
Kageyama (2008) em termos municipais seria necessária a disponibilidade de uma série de dados que não existem nesse nível no Brasil. Por essa razão foram necessárias adaptações nos indicadores propostos por Kageyama (2008) para que se tornasse viável o cálculo dos indicadores a partir dos municípios.

Assim, tendo como base a metodologia descrita, foram utilizados os indicadores (Quadro 1) para caracterizar o processo de desenvolvimento rural nos municípios do estado do Rio de Janeiro. As justificativas para a seleção dos indicadores apresentados no Quadro 1 podem ser buscadas em Kageyama (2008). 
Os dados utilizados nos indicadores presentes nos Fatores Condicionantes foram extraídos do: Instituto Nacional de Estudos e Pesquisas Educacionais (Inep), de 2010; Censo Demográfico, de 2010 e Censo Agropecuário, de 2006, ambos do Instituto Brasileiro de Geografia e Estatística (IBGE). Para o cálculo dos indicadores presente nas Características foram retirados do Censo Agropecuário de 2006. E para o cálculo dos indicadores dos Resultados foram retirados do Censo Demográfico anos 2000 e 2010 e Censo Agropecuário de 2006.

Vale destacar que os indicadores referentes ao Meio Ambiente que compõem a dimensão das Características foram os mais difíceis de serem adaptados, dada a escassez de dados em termos municipais; por essa razão foram estes que se afastaram em maior medida daqueles indicadores originalmente propostos por Kageyama (2008).

Após a coleta dos dados foi realizada uma análise do dendograma no software SPSS (Statistical Package for the Social Sciences) v. 22 com o objetivo de determinar o número de cluster mais adequado para ser utilizado na análise. Esse procedimento foi realizado para cada uma das três dimensões propostas (Fatores Condicionantes, Características e Resultados) definindo-se três clusters para Fatores Condicionantes, quatro clusters para características e três clusters para Resultados. No caso dos Fatores Condicionantes das 92 cidades que compõem o estado do Rio de Janeiro somente 75 foram consideradas, sendo que as demais não foram clusterizadas, uma vez que os dados não estavam adequados para tal. ${ }^{6}$ Devido à mesma situação foram consideradas 80 cidades para a formação dos clusters nas Características e 76 cidades no caso dos Resultados.

Após a definição do número de clusters, os dados foram submetidos à uma análise hieráquica de clusters no software Philcarto v. 5.73, que forneceu uma série de elementos estatísticos para análise, e o mapa dos aglomerados formados em cada uma das dimensões.

Por fim, buscou-se na literatura relacionada à história, economia e geografia do estado do Rio de Janeiro a explicação para a formação dos grupos homogêneos, uma vez que as semelhanças no perfil de desenvolvimento que aproximam as cidades que compóem cada grupo estão calcadas em questões históricas, econômicas e geográficas que marcam seu desenvolvimento, como ressalta Kageyama (2008).

6. Valores em formato de intervalos ou dados inexistentes.

\section{A dinâmica do desenvolvimento rural: análise das três dimensões}

Na sequência são apresentadas as caracterizações dos clusters formados a partir da análise estatística.

\subsection{Os fatores condicionantes}

Segundo Kageyama (2008), os indicadores propostos nos Fatores Condicionantes visam caracterizar a base demográfica e econômica, sob a qual se processa o desenvolvimento rural, ou seja, analisar o potencial de desenvolvimento, que permite promover ou retardar as características do território.

Dos 16 indicadores utilizados nesse quesito, somente a "área média dos estabelecimentos rurais" não estaria positivamente relacionada ao desenvolvimento rural 7 .

Os indicadores de 1 a 6 (Tabela 1) se referem aos Fatores Demográficos; de 7 a 11 se referem ao Isolamento Territorial e, de 12 a 16, à Presença da Agricultura Familiar. Segundo a Kageyama (2008), os indicadores de Isolamento Territorial buscam mensurar as distâncias econômicas dos contatos e da acessibilidade em geral, assim quanto menor o isolamento, maiores serão as possibilidades de um desenvolvimento rural que contemple diversificação, multifuncionalidade e progresso social. Os indicadores de Presença da Agricultura Familiar buscam mensurar aspectos que favorecem o desenvolvimento, como a diversificação agrícola, a menor concentração fundiária e a ocupação dos membros das famílias. Nos indicadores de Fatores Demográficos buscou-se mensurar aspectos que afetam o engajamento produtivo e os resultados de sua produção, tais como fecundidade, acesso a educação e base econômica.

A partir da clusterização, foram criados três grupos de cidades fluminenses (Figura 2).

No cluster 01 estão inseridos principalmente os municípios da região noroeste do estado e parte da região da serra próxima ao noroeste e alguns municípios do Vale do Paraíba. No cluster 02 estão inseridos, principalmente, municípios do Vale do Paraíba, centro-sul fluminense, bem como alguns municípios da baixada litorânea próxima à região norte do estado.

7. Quanto maior a área média, menor o potencial de desenvolvimento rural. 
Figura 2. Estado do Rio de Janeiro: clusters formados a partir dos indicadores dos Fatores Condicionantes

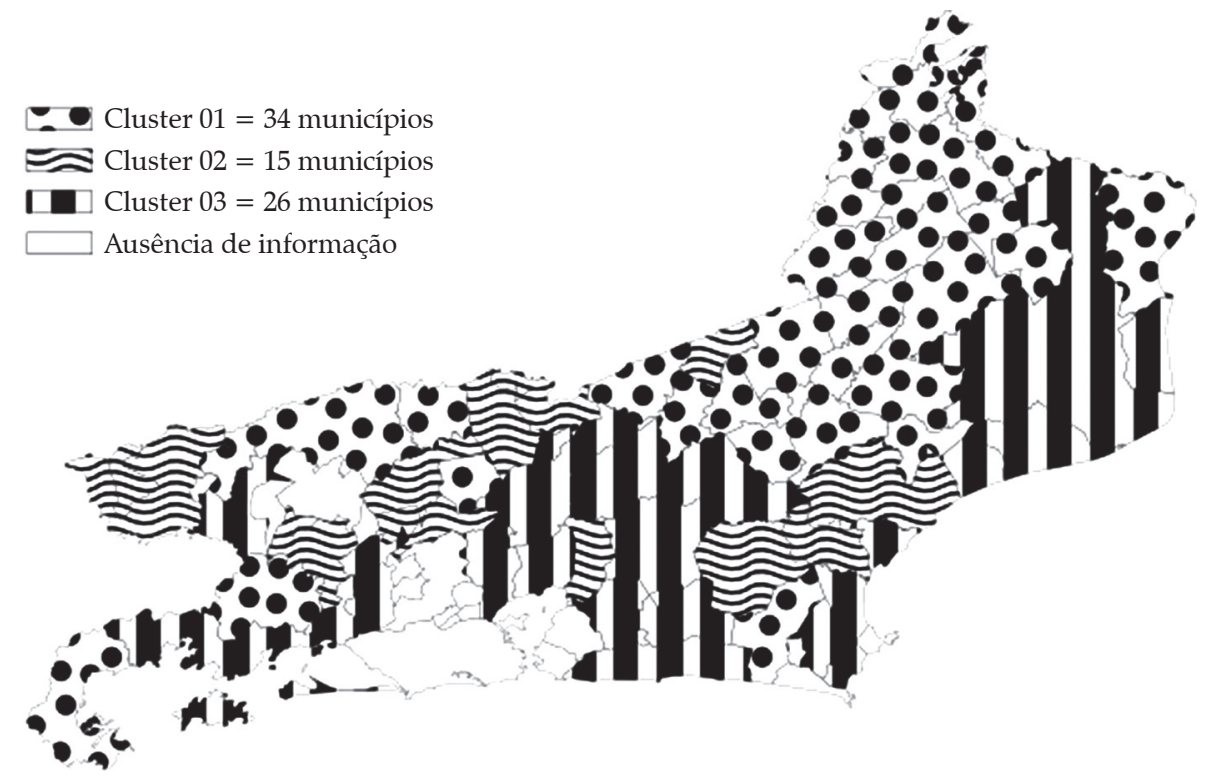

Fonte: Elaborado pela autora.

No cluster 03 estão inseridos parte do norte, da Costa Verde e metropolitana e parte sul da região Serrana. Na sequência são apresentados os valores médios dos indicadores (Tabela 1).

O cluster 01 apresentou o pior desempenho dentre os três, com valores acima da média somente em quatro dos 16 indicadores e também apresentou valor abaixo da média em área média dos estabelecimentos, o que é positivo para o desenvolvimento. Os indicadores positivos ao desenvolvimento estão concentrados naqueles referentes à Presença da Agricultura Familiar, em que, dos cinco indicadores, quatro deles são positivos,

Tabela 1. Indicadores de Fatores Condicionantes: valores médios dos indicadores segundo os clusters de municípios do estado do Rio de Janeiro

\begin{tabular}{|c|c|c|c|c|c|}
\hline & Indicadores & Todas & $\mathrm{C} 1$ & $\mathrm{C} 2$ & $\mathrm{C} 3$ \\
\hline 1 & $\%$ de estabelecimentos de ensino fundamental com mais de 30 alunos na área rural & 55,5 & 34,2 & 58,7 & 81,5 \\
\hline 2 & $\%$ de turmas não multisseriadas no ensino fundamental nas áreas rurais & 70,37 & 52,5 & 77,7 & 89,6 \\
\hline 3 & Razão docente por população de 5 a 14 anos por 1.000 pessoas na área rural & 104,3 & 75,2 & 65,3 & 164,9 \\
\hline 4 & Razão docente por estabelecimentos do ensino fundamental e médio na área rural & 6,1 & 3,9 & 6,2 & 8,9 \\
\hline 5 & Razão de dependência (ativos/inativos) na área rural & 1,8 & 1,8 & 1,9 & 1,8 \\
\hline 6 & PIBpc municipal (mil R\$/ano) & 23,0 & 13,4 & 25,5 & 34,2 \\
\hline 7 & \% da população municipal residente na área rural & 19,1 & 26,3 & 13,6 & 12,9 \\
\hline 8 & $\%$ dos domicílios rurais com telefone (fixo e celular) & 87,3 & 72,8 & 97,9 & 100,1 \\
\hline 9 & $\%$ dos domicílios rurais com internet & 7,2 & 3,5 & 10,0 & 10,6 \\
\hline 10 & Densidade demográfica $\left(\mathrm{hab} / \mathrm{km}^{2}\right)$ & 134,7 & 53,7 & 111,7 & 254,1 \\
\hline 11 & Veículos/km² & 39,5 & 14,6 & 29,3 & 77,9 \\
\hline 12 & $\%$ área plantada exceto as duas principais culturas & 39,4 & 45,3 & 41,5 & 30,3 \\
\hline 13 & $\%$ da área plantada em estabelecimentos rurais com até 10 hectares & 6,0 & 5,4 & 1,9 & 9,1 \\
\hline 14 & $\%$ do valor da produção com origem na agricultura familiar & 41,1 & 48,7 & 20,6 & 42,9 \\
\hline 15 & \% mão de obra familiar não assalariada na área rural & 89,1 & 89,6 & 85,6 & 90,5 \\
\hline 16 & Área média dos estabelecimentos agropecuários (ha) & 49,8 & 45,6 & 89,1 & 32,6 \\
\hline
\end{tabular}

Fonte: Inep/MEC, Censo Demográfico 2000 e 2010, Censo Agropecuário, 2006. Elaborado pela autora. 
demonstrando presença marcante da agricultura familiar na região comparativamente aos demais clusters. Vale ainda ressaltar que esse grupo é o que apresentou o maior percentual de população rural $(26,3 \%)$.

As regiões que se destacam dentro do cluster 01 são a noroeste e a parte da região Serrana mais próxima ao noroeste. A outra região que apresenta alguns municípios nesse cluster é a do médio Paraíba.

A região noroeste é considerada uma das mais pobres do estado. Seu cenário é de forte degradação ambiental e êxodo rural, tendo uma situação social dramática (TEIXEIRA, 2009) e uma estrutura fundiária baseada no binômio minifúndio - latifúndio com má utilização das terras (CIDE, 2009).

Essa foi uma das regióes onde a cafeicultura se implantou após a exaustão da terra no Vale do Paraíba (e a sua consequente redução da produtividade dos cafezais), tendo sua ocupação decorrente do surto cafeeiro. Contudo, com a migração da produção de café para São Paulo, os cafezais foram substituídos pela pecuária extensiva. O relevo acidentado e o clima tropical de altitude, com forte sazonalidade das chuvas e uma forma de plantio do café que favoreceu a erosão e reduziu, consequentemente, a fertilidade do solo, dificultaram a manutenção da produção. Assim, o noroeste reproduziu a mesma trajetória do Vale do Paraíba algumas décadas depois (ALENTEJANO, 2005). Melo e Parré (2007), a partir de um indicador de desenvolvimento rural, identificaram que os municípios a noroeste do estado do Paraná tiveram um desempenho inferior ao de outras regiões em termos de desenvolvimento rural. Para os autores, isso estaria relacionado à dificuldade que a região apresentou em transitar da crise cafeeira (anos 60/70) para um novo padrão de atividade agrícola. O solo arenoso teria inviabilizado a expansão de culturas anuais, fazendo com que a pecuária extensiva fosse a melhor opção ao declínio do café. Assim, identifica-se que a dinâmica pela qual passou a região do médio Paraíba e posteriormente o noroeste do estado do Rio de Janeiro, e que determinou, comparativamente a outras regiões do estado, um menor grau de desenvolvimento rural, esteve presente de forma similar no estado do Paraná.

Atualmente, a produção predominante na região noroeste é a pecuária leiteira extensiva, ao lado do crescimento da rizicultura, das lavouras de tomate e cana-de-açúcar (TEIXEIRA, 2009), tendo ainda fortes características rurais em função do distanciamento da região metropolitana.

A dinâmica das regiões rurais da região serrana localizada mais ao norte é similar aquela encontrada nas regiões norte e noroeste fluminense do que a dinâmica observada na da região serrana mais "próspera", localizada mais ao sul, próxima a região metropolitana. A região serrana mais a noroeste apresenta fraco desempenho econômico, em função da substituição da atividade cafeeira pela pecuária extensiva, em solos empobrecidos, trazendo baixos índices de produtividade, o que tem servido para forçar o êxodo de parcelas consideráveis da força de trabalho rural (MARAFON, 2011), tendo, portanto, uma trajetória similar àquela descrita em relação à região noroeste.

O cluster 03 apresenta a melhor situação, tendo somente três dos 16 indicadores abaixo da média. Certamente que as razões que levam as diferentes regiões que compõem esse grupo a terem os melhores condicionantes para o desenvolvimento rural são distintas. Uma primeira região que faz parte deste grupo é grande parte dos municípios do norte. Essa região do estado é tradicional na produção agropecuária e teve, na produção da cana-de-açúcar, um importante motor econômico no século XX. Num primeiro momento, essa produção de cana-de-açúcar se alicerçou nos grandes engenhos e na mão de obra rural. Posteriormente, com a mudança nos padrões técnicos de produção, a forma de produzir foi alterada, ganhando forma nas grandes usinas e no trabalho temporário materializado nos "boias-frias". A produção de cana-de-açúcar na região tem sido fortemente reduzida como consequência da redução dos estímulos do Proálcool e da baixa produtividade regional num contexto de acirramento da competição com outras regiões (AZEVEDO, 2004). Nota-se, contudo, que apesar da tradição na produção de cana-de-açúcar baseada outrora em latifúndios, há forte presença da agricultura familiar na região comparativamente a outros locais do estado, uma vez que, como se pode observar na Tabela 1, os indicadores referentes à presença da agricultura familiar são os maiores encontrados entre os clusters, inclusive aqueles referentes à área média dos estabelecimentos (valores abaixo da média dos clusters). Contudo, o indicador de diversificação (percentual de área com culturas exceto as duas principais) segue abaixo da média, indicando baixa diversificação comparativamente a outros clusters 
e que, no caso da região norte, pode refletir o predomínio da produção de cana-de-açúcar. Segundo Cruz (2006), as características do processo de modernização do setor agropecuário e agroindustrial da região norte fluminense agravaram os fenômenos do monocultivo, da concentração e fragmentação fundiárias e do êxodo rural. Seria, talvez, dessa falência dos sistemas de produção e processamento de cana acima citado, que teria surgido uma agricultura familiar mais presente comparativamente a outras regiões do estado.

Melo e Parré (2007) identificaram que, no norte pioneiro do Paraná, com a crise da cafeicultura, a região se voltou à produção de culturas de larga escala, como trigo, soja e cana, incorporando tecnologia e tendo como consequência o êxodo rural, ficando numa situação intermediária em termos de desenvolvimento rural. Essa situação é similar à encontrada no norte fluminense que, diante da mesma crise, se voltou à produção de cana-de-açúcar em moldes de larga escala, ocasionando também êxodo rural na região. Por outro lado, a participação da maioria dos municípios da região norte do estado no grupo com melhores indicadores (cluster 03) pode decorrer do fato de esses municípios terem acesso privilegiado aos royalties do petróleo, recursos que teriam impacto direto ou indireto em diferentes indicadores ligados ao isolamento territorial e a fatores demográficos, mas também em decorrência dos efeitos dos investimentos que são realizados na produção de petróleo e gás na região (aumento do emprego, aumento da renda e demanda pelos diferentes serviços e bens). Segundo Pacheco, "dos nove municípios do norte fluminense, cinco estão localizados na denominada Zona de Produção Principal da Bacia de Campos: Campos dos Goytacazes, Carapebus, Macaé, Quissamã e São João da Barra. Tal fato lhes confere maior participação no rateio final dos recursos de royalties. Já os municípios de Cardoso Moreira, Conceição de Macabu, São Fidélis e São Francisco de Itabapoana fazem parte da denominada Zona de Produção Limítrofe da Bacia de Campos, o que implica em menor repasse de royalties (quando comparado com os repasses obtidos pelos municípios da Zona de Produção Principal e Zona de Produção Secundária)". Ainda segundo esse autor, "os dados indicam que os royalties estão sendo gastos na ampliação da oferta de bens e serviços públicos, como se fossem recursos tributários", o que impactaria na oferta de serviços básicos, como educação, saúde, saneamento.
Uma segunda região pertencente ao cluster 03 é parte da serrana composta pelos municípios de Teresópolis, Petrópolis e Nova Friburgo. Esses municípios tiveram sua origem vinculada também à expansão cafeeira do século XIX. O acesso à capital do Rio de Janeiro através das ferrovias que transportavam o café permitiu o surgimento de indústrias, comércio e turismo na região (CARNEIRO; ROCHA, 2009). Alentejano (2005) aponta como aspectos que marcam o processo de desenvolvimento da região serrana os fatos: (i) o abastecimento alimentício da região metropolitana do Rio de Janeiro e (ii) ser um elo de ligação com as demais regiões do estado, já que duas das principais ligações rodoviárias cruzam a região, justificando o surgimento de atividades de apoio a circulação de mercadorias e serviços. Segundo Marafon et al. (2011), a região da serra deteve maior desenvolvimento das atividades produtivas em decorrência da industrialização nascente, da vinda dos colonos e da acelerada urbanização. Conterato, Schneider e Waquil (2009), a partir da análise de indicadores de desenvolvimento rural, identificaram que a microrregião de Caxias do Sul, localizada na região serrana do estado do Rio Grande do Sul, apresentou melhores indicadores de desenvolvimento rural que outras microrregiões analisadas em decorrência do desenvolvimento das atividades industriais e da concentração de comércio e serviços que tem tornado essa região um dos principais polos econômicos daquele estado. Nesse sentido, dinâmica similar pode ser identificada na região serrana fluminense "próspera", que também apresentou indicadores acima da média comparativamente as demais regiões do estado. Esta similaridade corrobora a afirmativa de que o desenvolvimento rural virtuoso pode estar associado à uma dinâmica econômica-produtiva diversificada da região considerada.

A presença da agricultura familiar na região está associada à topografia acidentada que não favoreceu a instalação de grandes propriedades, justificando a permanência de médias e pequenas propriedades mesmo diante da tendência à concentração fundiária vista em outras regiões do estado (CARNEIRO; ROCHA, 2009). A persistência e a força da agricultura familiar na região podem estar associadas, segundo Carneiro e Rocha (2009), à manutenção do tecido social em que a agricultura está calcada seja como renda principal, complementar ou como garantida de segurança alimentar das famílias. 
A região metropolitana é outra região pertencente ao cluster 03. Nessa região, a parte mais próxima à Baía da Guanabara, nas primeiras décadas do século, foram instalados alguns núcleos coloniais de pequenos produtores com o objetivo de abastecer a capital. Contudo, dada a proximidade com a cidade do Rio, a disputa pela posse da terra por especuladores e interessados em se instalar numa área com infraestrutura e perto da capital passa a predominar (ALENTEJANO, 2005) alijando o desenvolvimento agropecuário da região.

A atividade agropecuária na região é pouco praticada, mas apresenta, entretanto, uma produção de fruticultura e olericultura e até mesmo agricultura ecológica; porém, numa escala bem inferior àquela praticada na região serrana (TEIXEIRA, 2009). O urbano nessa região avançou sob o rural em decorrência da expansão imobiliária (MARAFON et al., 2011), mas também pelo alto grau de industrialização encontrado na região (TEIXEIRA, 2009).

Aqui cabe uma importante consideração: a região metropolitana fluminense possui elevado grau de urbanização, como já apontado anteriormente; Nesse sentido, a existência de um "continuum" entre o rural e o urbano é intensa; assim, não há como negar a forte influência das características urbanas da região na determinação dos indicadores, principalmente ligados aos aspectos demográficos e de isolamento territorial.

A região da costa verde, com exceção de Paraty, também faz parte do cluster 3 , sendo que, nessa região, a construção da BR 101 cortando o litoral sul levou ao avanço do turismo e da especulação imobiliária e a um processo de desruralização, vinculando o ordenamento territorial aos interesses do capital especulativo imobiliário ligado ao turismo (ALENTEJANO, 2005).

A atividade agrícola na região é marginal, se sobressaindo às atividades ligadas à indústria do turismo que, no caso dessa região, está ligado ao turismo de natureza (ecológico ou praia) e ao patrimônio histórico-cultural. É o turismo quem dinamiza os demais setores, inclusive a agricultura (MARAFON et al., 2011).

A atividade agrícola é limitada por estar inserida numa região com diversas unidades de conservação que são reservas de Mata Atlântica, destacando-se a agricultura extrativista com a exploração de palmito, coco e banana (TEIXEIRA, 2009). Além disso, como em outras regióes turísticas do estado, a intensa especulação imobiliária espreme ainda mais o rural, levando muitos produtores familiares a abandonar a atividade agrícola, quando não a saírem de suas terras (MARAFON et al., 2011).

Já o cluster 02 apresentou oito indicadores positivos em relação ao desenvolvimento rural e oito indicadores negativos ao desenvolvimento. Parte dos municípios pertencentes a esse cluster está localizado na região centro-sul fluminense, marcada pelo abandono dos cafezais, dada a migração do café para o estado de São Paulo, e sua substituição pela pecuária extensiva grande poupadora de mão de obra (ALENTEJANO, 2005)

\subsection{As Características}

Segundo Kageyama (2008), as Características constituem as condições para as diferentes trajetórias de desenvolvimento, que são próprias de cada região e que buscam ser captadas pelos indicadores.

Os dez indicadores utilizados nesta dimensão estão divididos em três aspectos: Diversidade da Agricultura - indicadores de 1 a 4; Ambientais - indicadores de 5 a 8 e Pluriatividade - indicadores de 9 a 11. Os indicadores do primeiro aspecto buscam identificar a "vocação" da região para agricultura ou pecuária e sua intensificação, entendendo que uma agricultura diversificada e produtiva seria a melhor situação para promoção do desenvolvimento rural. Os indicadores ambientais suscitam a importância da preservação do meio ambiente para o alcance do desenvolvimento rural. A pluriatividade está associada à diversificação das origens das rendas como forma de superação do estado de pobreza ou mesmo de capitalização.

A partir da clusterização foram criados quatro clusters. A Figura 3 indica uma predominância do cluster 03 , indicando uma trajetória de desenvolvimento rural semelhante para grande parte do estado, principalmente nas regiões norte, noroeste, centro, baixada litorânea e parte do Vale do Paraíba. Já o cluster 02 se concentra na região serrana mais ao sul. $\mathrm{O}$ cluster 01 está localizado principalmente na região metropolitana e o cluster 04 está disperso nas regiões sul e pouco ao norte do estado. Os valores médios das variáveis para os clusters e para todas as cidades são apresentados a seguir (Tabela 2).

Os clusters 01 e 02 apresentaram para a variável "relação entre área de lavoura e outros usos" valores (respectivamente 0,3 e 0,3) acima da média $(0,2)$ e, para a variável "razão entre pastagens plantadas e naturais", 
Figura 3. Estado do Rio de Janeiro: clusters formados a partir dos indicadores das Características

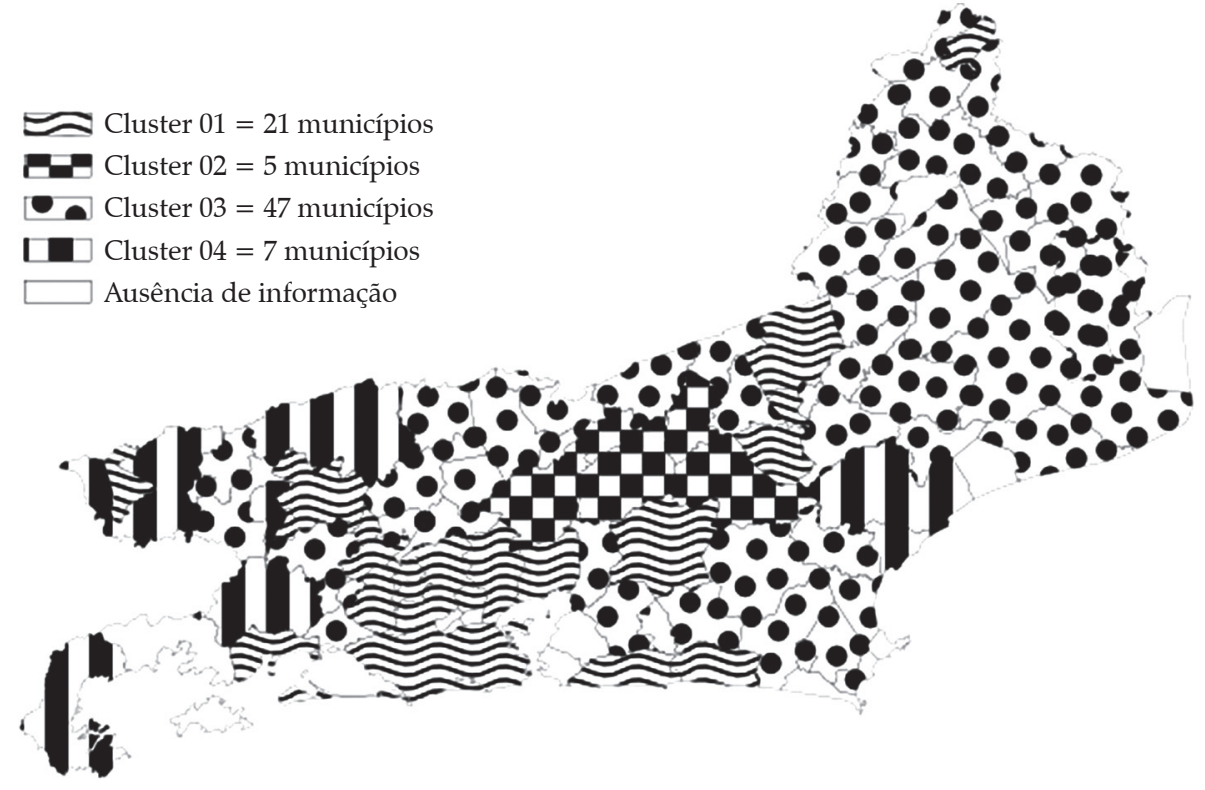

Fonte: Elaborado pela autora.

Tabela 2. Indicadores de Características: valores médios dos indicadores segundo os clusters de municípios do estado do Rio de Janeiro

\begin{tabular}{|c|c|c|c|c|c|c|}
\hline & Indicadores & Todas & C1 & $\mathrm{C} 2$ & $\mathrm{C} 3$ & $\mathrm{C} 4$ \\
\hline 1 & Relação entre área de lavoura e de outros usos & 0,2 & 0,3 & 0,3 & 0,1 & 0,1 \\
\hline 2 & Razão entre pastagens plantadas e naturais & 1,0 & 0,8 & 0,9 & 1,0 & 1,5 \\
\hline 3 & Razão entre o valor da produção e área (ha) & 677,6 & 875,1 & 2460,7 & 462,8 & 253,9 \\
\hline 4 & Razão do valor da produção e pessoas ocupadas ( $\mathrm{R} \$$ pessoa) & 817,3 & 725,6 & 1347,0 & 819,3 & 700,1 \\
\hline 5 & \% da área dos estabelecimentos rurais com matas e/ou florestas & 18,1 & 21,9 & 30,8 & 12,9 & 32,4 \\
\hline 6 & $\%$ de estabelecimentos rurais que utilizam plantio em nível & 21,8 & 27,3 & 45,5 & 16,9 & 21,2 \\
\hline 7 & $\%$ de estabelecimentos que protegem ou conservam as encostas & 4,5 & 4,1 & 6,7 & 4,2 & 6,6 \\
\hline 8 & $\%$ dos estabelecimentos que utilizam a rotação de cultura & 10,7 & 9,7 & 47,6 & 7,6 & 8,2 \\
\hline 9 & $\%$ de estabelecimentos rurais são pluriativos & 25,2 & 27,3 & 15,4 & 25,3 & 24,7 \\
\hline 10 & $\begin{array}{l}\% \text { do pessoal ocupado apenas em atividades não agropecuárias nos estabeleci- } \\
\text { mentos rurais }\end{array}$ & 4,1 & 7,5 & 1,9 & 2,9 & 3,3 \\
\hline 11 & \% da receita dos estabelecimentos rurais com origem do trabalho não agrícola & 3,9 & 3,7 & 5,5 & 1,9 & 16,5 \\
\hline
\end{tabular}

Fonte: Censo Agropecuário 2006 (IBGE). Elaborado pela autora.

valores $(0,8$ e 0,9$)$ abaixo da média $(1,0)$, indicando que nessas duas regiões há o predomínio de lavouras em relação às pastagens comparativamente aos demais. A agricultura dos clusters 01 e 02 seria intensiva por gerar valor da produção por hectare acima da média, sendo a do cluster 02 a mais intensiva dentre todos. No caso do cluster 02 , a atividade agrícola seria ainda intensiva em trabalho por gerar um valor da produção por pessoa ocupada (R\$1.347,00) bem acima da média ( $\mathrm{R} \$ 817,3)$.
Os clusters 03 e 04 apresentaram valores (1 e 1,5 respectivamente) próximos à média (1) para a variável "razão entre pastagens plantadas e naturais" e valores $(0,1$ e 0,1 respectivamente) abaixo da média $(0,2)$ para "relação entre área de lavoura e de outros usos" indicando, portanto, um predomínio da atividade pecuária comparativamente aos demais clusters. Contudo, em ambos o valor da produção por hectare ( $\mathrm{R} \$ 462,8$ e $\mathrm{R} \$ 253,9$ respectivamente) ficou abaixo da média 
(R\$ 677,6), indicando pecuária extensiva. O valor $(\mathrm{R} \$ 700,1)$ abaixo da média $(\mathrm{R} \$ 817,3)$ da variável produção por pessoa ocupada indicaria, ainda, no caso do cluster 04, uma baixa produtividade da mão de obra. Nesse sentido, o que se evidencia é que, no caso do cluster 03, o desenvolvimento rural é marcado pela pecuária extensiva em área, mas de maior produtividade relacionada à mão de obra e que, no caso do cluster 04, sua trajetória de desenvolvimento é marcada por uma pecuária de caráter extensivo e de baixa produtividade da mão de obra.

Em relação aos indicadores ambientais, o cluster 02 se destaca por apresentar todos os quatro indicadores com valores bem acima da média comparativamente aos demais clusters, indicando que a preservação ambiental tem permeado o processo de desenvolvimento rural na região. Situação oposta estaria presente no cluster 03 , uma vez que todos os indicadores ambientais encontram-se com valores abaixo da média, indicando que a trajetória de desenvolvimento rural dessa região tem sido marcada pela ausência de preocupação ambiental. Já no caso dos clusters 01 e 04, a situação ambiental seria intermediária, uma vez que nos dois clusters existem dois indicadores acima da média e dois indicadores abaixo da média.

O cluster 02 abarca principalmente a região serrana que é marcada pela presença de unidades de conservação e pela presença de atividade agrícola intensa comparativamente às demais regiões, mas que é desenvolvida principalmente por agricultores familiares num contexto de valorização da paisagem natural pelos turistas, o que tem como consequência a existência de uma maior preocupação com a questão ambiental, mas também a disseminação de práticas agrícolas menos impactantes ao meio ambiente como a produção orgânica e agroecológica (CARNEIRO; ROCHA, 2009).

No caso do cluster 03, que abarca as regiões norte, noroeste, centro-sul e baixadas, o desempenho ruim na dimensão ambiental pode estar (com exceção da região das baixadas) associada à degradação do solo gerada primeiramente pelas atividades monocultoras de café e cana-de-açúcar e que posteriormente foi agravada pela prática da pecuária extensiva que passa a dominar a paisagem da região.

Em relação à pluriatividade, o cluster 01 apresentou valores acima da média em dois dos três indicadores, enquanto os demais apresentaram somente um dos três indicadores acima da média, indicando que, comparativamente, o cluster 01 teria a pluriatividade mais presente em seu processo de desenvolvimento. No caso do cluster 01, os indicadores que ficaram acima da média foram o "percentual de estabelecimentos pluriativos"8 e o "percentual de pessoas ocupadas apenas em atividades não agropecuárias nos estabelecimentos rurais". No caso do terceiro indicador de pluriatividade, "percentual da receita do trabalho não agrícola no estabelecimento", o valor de 3,7\% ficou bem próximo à média, que foi de 3,9\% .

Sintetizando, o cluster 01 teria sua trajetória de desenvolvimento, comparativamente aos demais clusters, marcada pela maior presença da pluriatividade e pela agricultura mais intensiva. A trajetória do desenvolvimento do cluster 02 seria caracterizada pela agricultura intensiva com forte preocupação ambiental. O cluster 03 tem sua trajetória de desenvolvimento marcada pela pecuária extensiva com baixa preocupação ambiental. E o cluster 04 tem sua trajetória marcada pela pecuária extensiva.

No caso do cluster 02, que agrega boa parte da região serrana do estado, essa característica do processo de desenvolvimento calcada na produção agrícola mais intensiva com preocupação ambiental quando se compara com outras regiões está relacionada à dinâmica territorial que envolve uma intensa produção agrícola centrada em pequenos estabelecimentos com mão de obra familiar, associada à existência de várias unidades de conservação ambiental. Essas unidades de conservação associadas à exploração do turismo inibem a atividade agrícola intensiva em favor da exploração do turismo, pressionando para formas de produção agrícola associadas a produção orgânica e/ou agroecológica, que estão mais ligadas ao turismo ecológico (CARNEIRO; ROCHA, 2009). Essa região tem um importante papel no abastecimento de hortícolas no estado, principalmente na região próxima à cidade do Rio de Janeiro.

Como tem sido destacado na literatura fluminense sobre pluriatividade (MARAFON, 2007; RUA, 2002; CARNEIRO; ROCHA, 2009), a serrana seria a principal região do estado onde o fenômeno da pluriatividade se manifestaria de forma intensa, dada a conjunção de alguns fatores: a existência de muitos estabelecimen-

8. Aqueles em que ao menos um membro da família declarou ter atividade remunerada fora do estabelecimento agropecuário. 
tos familiares, o intenso turismo que leva ao aumento de oportunidades de trabalho não agrícolas e a revalorização do turismo rural, bem como a ampliação de chácaras e sítios de lazer que também ampliam as oportunidades de trabalho não agrícolas. Mas, ao contrário do esperado, dois dos três indicadores de pluriatividade não apresentaram em sua maioria valores acima da média ou mesmo próximos a média.

É no cluster 01, que abarca parte da região metropolitana, parte da região central (Barra do Piraí, Mendes, Paulo de Frontin) e parte da serrana mais ao norte (Cantagalo, Cordeiro e Bom Jardim), onde a pluriatividade se manifesta de forma mais intensa comparativamente às demais regiões. A razão pela qual o indicador de "estabelecimentos pluriativos" é maior na região metropolitana está associada à exploração das áreas rurais com fins de moradia para os trabalhadores urbanos, em virtude da valorização imobiliária e, com efeito, a ampliação das áreas urbanas sobre as áreas rurais, possibilitando moradia a menor custo na periferia. Essa realidade teria influência direta, portanto, no fato de o indicador "percentual do pessoal ocupado apenas em atividades não agropecuárias" estar acima da média do estado. Como coloca Marafon (2007),

as transformações no espaço rural, como a prática do turismo rural e a disseminação de empregos não agrícolas, encontram-se associadas ao intenso processo de urbanização (p. 96).

Alentejano (2005, p. 53), citando Brito e Inocêncio (1988, p. 115), coloca que "o processo de valorização das terras associado à expansão da Grande Rio tem tido papel muito significativo nas transformações que se vê operando no meio rural fluminense".

O cluster 03 também apresentou um percentual de estabelecimentos pluriativos acima da média, o que significa que, em boa parte do interior do estado (região que abarca norte, noroeste, baixadas, centro-sul), esse fenômeno tem se evidenciado. Em parte, isso pode decorrer de mudanças relacionadas à desmetropolização que viria acontecendo recentemente não somente na esfera da produção, mas também da circulação com o avanço do turismo para o interior. Segundo Teixeira (2009), o turismo rural tem engendrado uma série de mudanças no espaço agrário, contribuindo para uma nova relação rural-urbano e proporcionando uma revalorização do meio rural, simultaneamente ao esvaziamento das práticas agrícolas.

\subsection{Os resultados}

Os Resultados associados a um processo de desenvolvimento rural estariam ligados à melhoria de bem-estar da população rural.

“O processo de desenvolvimento rural deve equilibrar os benefícios ao território e à população de forma a preservar o meio ambiente, dinamizar a economia e melhorar as condições de vida e bem-estar" (KAGEYAMA, 2008, p. 157).

Dessa forma, espera-se que um processo virtuoso de desenvolvimento rural implique na redução da emigração rural, na elevação da renda e na redução da pobreza, melhoria da qualidade de vida e da educação.

Os indicadores utilizados estão divididos e três aspectos: Escolaridade de 1 a 3; Êxodo Rural de 4 a 5; Renda e Redução da Pobreza de 6 a 9 e a partir da clusterização foram criados quatro clusters nessa dimensão.

A Figura 4 indica a predominância do cluster 02, cuja área domina as regiões norte e noroeste do estado, bem como parte da região da serra próxima a essas áreas. O cluster 01 em sua maioria agrega cidades da região central indo para o sul do estado. Já o cluster de 03 agrega cidades da região sul, litoral próximo ao norte e algumas outras cidades dispersas.

Os valores médios dos indicadores para os clusters e para todas as cidades são apresentados a seguir (Tabela 3).

Em relação aos indicadores de escolaridade, o grupo 01 apresentou dois indicadores acima da média enquanto os demais apresentaram somente um indicador com valor acima da média. Já em relação aos indicadores do êxodo rural, somente o cluster 03 apresentou aumento da população, enquanto os demais clusters apresentaram redução; portanto, o cluster 03 demonstrou um comportamento dissonante da variação negativa que caracteriza a variação da população rural em geral. O cluster 02 apresentou desempenho abaixo da média em ambos indicadores de êxodo rural.

Em relação aos indicadores ligados à renda e à qualidade de vida, o pior desempenho foi o do cluster 02 que apresentou todos os indicadores com valores abaixo da média enquanto o melhor desempenho foi do cluster 03, que teve três indicadores apresentando valores bem acima da média. 
Figura 4. Estado do Rio de Janeiro: clusters formados a partir dos dados dos indicadores dos resultados

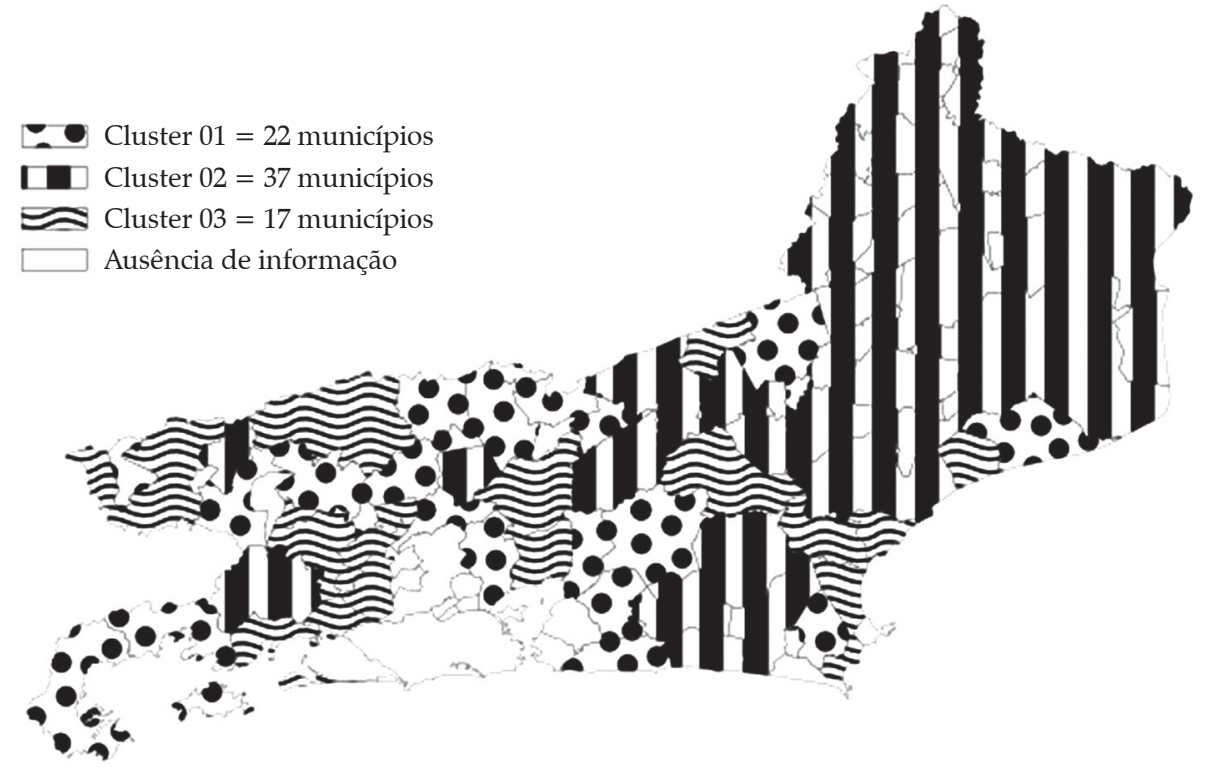

Fonte: Elaborado pela autora.

Tabela 3. Indicadores de Resultado: valores médios dos indicadores segundo os clusters de municípios do estado do Rio de Janeiro

\begin{tabular}{llcccc}
\hline & \multicolumn{1}{c}{ Indicadores } & Todas & C1 & C2 & C3 \\
\hline 1 & Taxa (\%) de escolaridade do rural & 34,7 & 39,1 & 32,5 & 33,9 \\
2 & Razão entre o número de pessoas adultas com 8 anos ou mais de estudo & 6,1 & 4,8 & 7,9 & 4,1 \\
3 & Taxa (\%) de alfabetização no rural & 86,6 & 88,2 & 83,5 & 91,2 \\
4 & Variação (\%) da população rural entre 2000 e 2010 & $-6,1$ & $-25,6$ & $-11,1$ & 30,0 \\
5 & Média de moradores nos domić́lios rurais & 3,7 & 3,4 & 3,3 & 3,3 \\
6 & Índice de Desenvolvimento Humano Municipal - IDHm & 0,71 & 0,71 & 0,7 & 0,7 \\
7 & Índice de Condições de Vida - INIVI & 64,9 & 66,7 & 60,4 & 72,3 \\
8 & \% da receita dos estabelecimentos rurais vindas do trabalho. & 96,9 & 98,2 & 96,5 & 96,1 \\
9 & Rendimento nominal médio (R\$) mensal das pessoas com 10 ou mais anos & 431,8 & 458,1 & 375,0 & 524,3 \\
\hline
\end{tabular}

Fonte: Censo Demográfico 2000 e 2010, Censo Agropecuário, 2006, PNUD, 2010, IBGE, 2010. Elaborado pela autora.

Em suma, o que se evidencia a partir dos dados é que o cluster 02 apresentou o pior desempenho, tendo somente um indicador acima da média. Os clusters 01 e 03 apresentaram a grande maioria dos indicadores acima da média, sendo que, no caso do cluster 03 , foram os maiores valores encontrados, principalmente nos itens renda e redução da pobreza. Destaca-se que somente no cluster 03 foi observado aumento da população rural, enquanto no cluster 01 observou-se a maior redução de população rural. De forma geral, os municípios tanto o cluster 01 como o 03 estão dispersos nas regiões mais ao centro-sul do estado, não sendo possí- vel identificar fatores comuns a esses municípios que expliquem suas posições nos grupos.

$\mathrm{O}$ cluster 02 , que abarca principalmente as regiões norte, noroeste e a serrana mais ao norte, apresentou o pior desempenho em relação aos Resultados. Essa situação pode estar associada à herança agrícola e agrária da região (noroeste e serrana a norte), que teve no seu passado a exploração da cana-de-açúcar e café nos moldes tradicionais da grande propriedade, aspectos que já foram tratados ao longo do texto. No caso do norte fluminense, além da queda de produtividade da cana-de-açúcar, produto ainda importante na agropecuária 
da região, o alto grau de desemprego sazonal tem como consequências a pauperização, o desenraizamento e o deslocamento do trabalhador rural para as periferias das cidades (MARAFON et al., 2011). A maior presença da agricultura familiar na região norte comparativamente às demais regiões não foi suficiente para determinar um bom desempenho dos indicadores de Resultados.

\section{Conclusões}

Diversos trabalhos têm sido publicados nos últimos anos com o objetivo de mensurar indicadores ou índices de desenvolvimento rural em estados, territórios ou municípios. Contudo, nenhum deles, exceto o de Kageyama (2008) e o presente trabalho, tratam o desenvolvimento rural como um processo e não como fim (resultados). Essa metodologia processual permite compreender melhor as raízes e os caminhos que o desenvolvimento rural têm trilhado nos diferentes territórios, gerando, assim, informações mais qualificadas que podem ser utilizadas para ações públicas ou privadas mais efetivas, que promovam um desenvolvimento rural virtuoso.

Contudo, no Brasil, são grandes as dificuldades na construção de indicadores de desenvolvimento rural em nível municipal, dada a inexistência de bancos de dados atualizados (ou não) em diferentes aspectos da realidade esfera municipal. Assim, por exemplo, no caso do estado do Rio de Janeiro haveria a necessidade de se considerar indicadores que envolvessem a questão da violência, dada a presença deste fenômeno nas áreas rurais das diferentes regiões; contudo, não há como incorporar tal aspecto aos indicadores, pois não estão disponíveis para consulta pública dados municipais e com recorte rural para tal tema.

Outro aspecto importante a ser destacado é a dificuldade em definir mais claramente as trajetórias pelas quais o desenvolvimento rural se processa nos territórios, isso porque os indicadores de "Características" que, a priori, deveriam permitir traçar esse caminho, são insuficientes para essa clareza, pois se referem a informações de um dado momento (uma fotografia) e não em diferentes momentos, o que seria mais adequado, pois permitiria uma melhor identificação de uma trajetória.

Em relação ao estado do Rio de Janeiro, identificou-se uma realidade heterogênea no espaço rural, convivendo com situações em que se observa um desenvolvimento rural virtuoso calcado em Fatores Condicionantes sólidos e em outras regiões um processo de desenvolvimento fraco, calcado num passivo deixado pelos ciclos econômicos vinculados a produtos de exportação (cana e café). Tal constatação consolida a necessidade de que as políticas públicas voltadas às áreas rurais sejam espacializadas, ou seja, que considerem as diferentes realidades locais.

A partir da análise dos indicadores, o que se observa é que a região noroeste, com o passivo deixado pelo ciclo do café, parte de uma situação condicionante para o desenvolvimento rural inferior ao das demais regiões do estado que, associado à uma pecuária extensiva, teriam levado a indicadores de Resultados abaixo da média do estado. Essa situação, contudo, não é única, como pontuado ao logo do texto, tendo a região noroeste do Paraná passado por situação similar. Essa constatação é importante por permitir compreender que uma mesma situação (o fim do ciclo do café) pode gerar externalidades em diferentes locais com características diferentes.

No caso da região norte, a situação difere um pouco, na medida em que os indicadores de Fatores Condicionantes estariam acima da média; contudo, a pecuária extensiva teria contribuído para que os indicadores de Resultados ficassem ruins (abaixo da média).

A situação da região serrana é dupla, uma vez que contempla duas realidades distintas que são captadas pelos indicadores: a parte da serrana mais próxima ao noroeste e a região mais próxima à metropolitana. No caso da região mais próxima ao noroeste, os municípios apresentam indicadores de Fatores Condicionantes abaixo da média que, associados à pecuária extensiva, na maioria dos municípios teriam levado os indicadores de Resultados abaixo da média. Já no caso da região serrana mais próxima à metropolitana, os indicadores de Fatores Condicionantes acima da média associados a um perfil agrícola mais intensivo com preocupação ambiental teriam levado a Resultados acima da média, exceto no caso de Teresópolis. Vale ressaltar que a região serrana é marcada por atividades fabril e comercial intensas, e essas características contribuíram para o desempenho dos indicadores de desenvolvimento rural da região. Essa constatação é similar àquela encontrada por Conterato, Schneider e Waquil (2009) em relação à microrregião de Caxias do Sul (RS). Dessa forma, infere-se que é de fundamental impor- 
tância para o desenvolvimento rural de um território a conformação dos aspectos do território não ligados de forma propriamente dita com o rural, como são os casos citados anteriormente.

No caso da região metropolitana, o que se percebe é que os Fatores Condicionantes ficariam acima da média associados ainda à uma pluriatividade bastante presente; contudo, a ausência de dados de muitos municípios associada à diversidade de situações em termos de Resultados tornam difícil qualquer associação.

Em relação à região do médio Paraíba, a falta de dados em relação aos indicadores de Fatores Condicionantes para alguns municípios e a presença de diferentes situações nos municípios não permitem especulações sobre os Fatores Condicionantes. Nessa região, os Resultados apresentam indicadores acima da média para a maioria dos municípios, denotando o alcance de melhores níveis de desenvolvimento rural comparativamente a outras regiões do estado. Isso pode estar associado à proximidade da realidade rural com as atividades fabris e de prestação de serviços que são características da região, demonstrando a interferência positiva da diversificação das atividades produtivas para um desenvolvimento rural virtuoso.

Por fim, vale destacar que nem sempre é possível, como colocado anteriormente, ter clareza sobre os encadeamentos entre Fatores Condicionantes, Características e os Resultados, o que, por sua vez, é um limitante, mas não invalida por completo a análise, uma vez que diferentes compreensões sobre os processos de desenvolvimento rural nas diferentes regiões ainda podem ser extraídas.

\section{Referências}

ALENTEJANO, P.R. A evolução do espaço agrário fluminense. GEOgraphia, ano 7, n. 13, 2005.

ARAUJO, C.A.L. Desenvolvimento rural: uma análise de indicadores populacionais, sociais, econômicos e ambientais. Universidade Estadual de Montes Claros. Dissertação de Mestrado (Desenvolvimento Social), 2014.

AZEVEDO, H.J. Uma análise da cadeia produtiva da cana-de-açúcar na região Norte Fluminense. In: PESSANHA, R.M., SILVA NETO, R. (Orgs.) Economia e desenvolvimento no Norte Fluminense: da cana de açúcar aos royalties do petróleo. Campos dos Goytacazes-RJ: WTC Editora, 2004.

CARNEIRO, M.J.; ROCHA, B.N.R. Limites e possibilidade da construção de "territórios de desenvolvimento" na Região Serrana do Rio de Janeiro. Politica e Sociedade, n. 14, abr. 2009.

CENSO AGROPECUÁRIO. Resultados do universo. Rio de Janeiro: IBGE, 2006. Disponível em: < http://www. ibge.gov.br>. Acesso em: fev. 2016.

CENSO DEMOGRÁFICO 2010. Características da população e dos domicílios: resultados do universo. Rio de Janeiro: IBGE, 2011. Disponível em: < http://www. ibge.gov.br/home/estatistica/populacao/censo2010/ caracteristicas_da_populacao/resultados_do_universo. pdf $>$. Acesso em: mar. 2013.

CEPERJ - Centro de Estatísticas, Estudos e Pesquisas. Valor adicionado bruto a preços de mercado. 2009. Disponível em: http://www.fesp.rj.gov.br/. Acesso em: fev. de 2016.

. Mapa do Estado do Rio de Janeiro - Regióes de Governo e Municípios. 2013. Disponível em: <www. ceperj.rj.gov.br/ceep/info_territorios/Reg\% 20 Gov_2013.pdf>. Acesso em: jañ. 2018.

CHALITA, M. A. N. Desenvolvimento rural, agricultura e natureza: novas questões de pesquisa. Agricultura em São Paulo, São Paulo, v. 52, n. 1, p. 97-11, jan./jun. 2005.

CIDE. Estado do Rio de Janeiro Regiões de Governo (descrição), 2009. Disponível em: <http://www.cide. rj.gov.br/download/Regioes_de_Governo_2009.pdf $>$. Acesso em: out. 2015.

CONTERATO, M.A.; SCHNEIDER, S.; WAQUIL, P.D. Desigualdade regionais de desenvolvimento rural do Rio Grande do Sul: uma proposta de análise multidimensional a partir de três microrregiões. Ensaios FEE, v. 39, p. 615-654, 2009.

CRUZ, J.L.V. Origem, natureza e persistência das desigualdades sociais no Norte Fluminense. In: CARVALHO, A.M.; TOTTI, M.E.F. (Orgs.). Formação histórica e econômica do Norte Fluminense. Rio de Janeiro: Garamond, 2006.

GRAZIANO, J.G.; DEL GROSSI, M.E. A pluriatividade na agropecuária brasileira em 1995. In: XXXVI Congresso da Sociedade Brasileira de Economia e Sociologia Rural, 1998, Brasília - DF. Vol. 2, p. 635-646. 1998.

IBGE - Instituto Brasileiro de Geografia e Estatística. Estados mais pobres aumentam participação no PIB em dez anos, aponta IBGE, 2014. Disponível em: <http:// 
economia.uol.com.br/noticias/redacao/2014/11/14/ estados-mais-pobres-aumentam-participacao-no-pibem-dez-anos-aponta-ibge.htm >. Acesso em: mar. 2016.

INSTITUTO NACIONAL DE ESTUDOS E PESQUISAS EDUCACIONAIS. Censo escolar: resultados. Brasília: MEC, 2010.

KAGEYAMA, A. Desenvolvimento rural: conceito e um exemplo de medida. In: XLII Congresso da Sociedade Brasileira de Economia e Sociologia Rural, 2004, Cuiabá. "Dinâmicas Setoriais e Desenvolvimento Regional", 2004.

. Desenvolvimento rural no Rio Grande do Sul. In: SCHNEIDER, S. (Org.). A diversidade da agricultura familiar. Porto Alegre: UFRGS Editora, 2006.

- Desenvolvimento rural: conceitos e aplicação ao caso brasileiro. Porto Alegre: UFRGS Editora, 2008.

MARAFON, J.G. Turismo em áreas rurais no Rio de Janeiro. Ciencias Sociales Online, v. I, n. 2, p. 85-102, 2007.

. et al. Geografia do estado do Rio de Janeiro. Rio de Janeiro: Gramna, 2011.

MELO, C.O.; PARRÉ, J.L. Índice de desenvolvimento rural dos municípios paranaenses: determinantes e hierarquização. Revista de Economia e Sociologia Rural, Brasília, v. 45, n. 2, abr./jun. 2007.

MELO, R.F. Análise do desenvolvimento rural na região do Triângulo Mineiro e Alto Paranaíba: caracterização dos municípios com base em indicadores populacionais, econômicos, ambientais e bem-estar social. Dissertação (Mestrado) - Universidade Federal de Uberlândia, 2005.

MOREIRA, R. Uma análise crítica do modelo de desenvolvimento do estado do Rio de Janeiro. In: MOREIRA, R. et al. Anais do Seminário. Niterói: EDUFF, 2001. p. 127-132.

NAVARRO Z. Desenvolvimento rural no Brasil: os limites do passado e os caminhos do futuro. Estudos Avançados, v. 15, n. 43, 2001.

NEY, V.S.P. Atividades agrícolas e não agrícolas no meio rural do estado do Rio de Janeiro. Tese (Doutorado em
Produção Vegetal) - Universidade estadual do Norte Fluminense, 2010.

PACHECO, C.A.G. O impacto dos royalties do petróleo no desenvolvimento econômico dos municípios da região norte fluminense. In: Anais do $3^{\circ}$ Congresso Brasileiro de P\&D em Petróleo e Gás. Salvador (BA). 2005.

RUA, J. Urbanidades e novas ruralidades no Estado do Rio de Janeiro: algumas considerações teóricas. In: MARAFON, G.J.; IBEIRO, M.F. (Orgs.). Estudos de Geografia Fluminense. Rio de Janeiro: Livraria e Editora Infobook, 2002.

Urbanidades no rural em um trecho da região serrana fluminense - a rodovia TeresópolisNova Friburgo. In: I Encontro de Grupos de Pesquisa - Agricultura, Desenvolvimento Regional e Transformações Sócio-Espaciais, Rio de Janeiro, 2005.

- Urbanidades no rural: o devir de novas territorialidades. CAMPO-TERRITÓRIO: Revista de Geografia Agrária, Uberlândia, v. 1, n. 1, p. 82-106, fev. 2006.

SILVA, F. F. Distribuição de crédito para a agricultura familiar: um estudo do PRONAF a partir de um indicador de desenvolvimento rural. Dissertação (Mestrado) Universidade Federal de Uberlândia, 2006.

SOBRAL, B.L.B. Limites ao desenvolvimento do estado do Rio de Janeiro: aspectos estruturais de seu processo de industrialização no período recente. Econômica, Rio de Janeiro, v. 11, n. 2, p. 133-154, dez. 2009.

TEIXEIRA, V.L. Novos contornos ocupacionais no meio rural fluminense: estudo sobre a pluriatividade entre agricultores familiares. 2009. Tese (Doutorado em Ciências Econômicas) - UNICAMP, 2009.

VEIGA, J.E. A face rural do desenvolvimento: natureza, território e agricultura. Porto Alegre: Editora da UFRGS, 2000.

WYE GROUP. Statistics on rural development and agricultural household income. Nações Unidas, 2011. Disponível em: <http://www.fao.org/wairdocs/ am087e/am087e.pdf>. Acesso em: mar. 2016.

Todo o conteúdo deste periódico, exceto onde estiver identificado, está licenciado sob uma Licença Creative Commons (cc by 4.0). 